\title{
Spectrofluorometric characteristics of fluorescent dissolved organic matter in a surface microlayer in the Southern Baltic coastal waters
}

\author{
V. Drozdowska \\ drozd@iopan.gda.pl
}

\section{P. Kowalczuk}

\section{Józefowicz}

Institute of Oceanology, Polish Academy of Sciences, Sopot, Poland

Institute of Oceanology, Polish Academy of Sciences, Sopot, Poland

This paper presents results of characterization of Dissolved Organic Matter (DOM) using fluorescence spectroscopy in the surface microlayers (SML) and subsurface layers (SS) in the Baltic Sea. Samples for spectroscopic measurements were collected during five research cruises in April/May and October 2013 and 2014 in a surface microlayer and a subsurface layer at a depth of $1 \mathrm{~m}$ along two transects from the river outlets to the open sea. The first transect was located from the Vistula River outlet to the Gdańsk Deep and the second transect was located from the Łeba River outlet to Słupsk Furrow. Results indicated that DOM fluorescence intensity in the SML is higher by $20 \%$ compared to the SS. The Humification Index, HIX values were lower in SML than SS by $13 \%$. That indicates that SML is depleted in molecules with high molecular weight and higher aromaticy. The inverse relationship of fluorescence intensity of dominant peaks with salinity both in SML and SS suggests that FDOM variability is regulated mostly by terrestrial DOM input.

[DOI: http://dx.doi.org/10.2971/jeos.2015.15050]

Keywords: Excitation-emission spectra, fluorescence spectroscopy, chromophoric organic matter, seawater

\section{INTRODUCTION}

The surface layer of the sea, being the boundary between the atmosphere and the sea, covers more than $70 \%$ of the Earth's surface. A sea surface microlayer (SML) is a few millimeters of an upper ocean surface [1] in direct contact with an atmosphere, which physicochemical and biological properties are clearly and measurably different from the underlying water [2]. The surface microlayer is almost ubiquitous and cover most of the surface of the ocean, even under conditions of high turbulence [3]. It is an extremely important boundary layer because of its role in the natural processes of the Earth, including the exchange of energy, mass and momentum between the sea and the atmosphere, transformation and circulation of organic matter as well as the exchange of gases and aerosol generation. The SML is disrupted by breaking waves, that disperse the SML material into the subsurface layers, to a depth of a few meters, from which escapes to the surface in the membranes of bubbles produced by breaking waves. During lifetime of a bubble both dissolved and small particles located in a water column accumulate on its surface. "Bubblescavenging" process is the key to the cycling of surface active material in the upper ocean [4].

In coastal waters of high biological activity, the natural slicks are observed in the SML (possible to see by a naked eye), resulted from greater amounts of hydrocarbons in the surface microlayer, accumulated during phytoplankton blooms [5]. Molecules that create a SML are called surfactants and their main sources are: (i) dissolved and suspended organic endproducts of marine phytoplankton decomposition, (ii) orga- nic matter coming from the lands (natural/terrestrial and anthropogenic) and (iii) anthropogenic and natural oil spills. They are a mixture of organic compounds rich in lipids (fatty acids, sterols), polymers and humic substances (fulvic and humic acids) and their proportions affect the surface films elasticity and other SML properties [6]. Surface microlayers result from the accumulation of both: discrete molecules, DOM, and larger particles, that consists of mixture of hydrophilic and hydrophobic or amphiphilic molecules, to form the surfaceactive structures that extend into subsurface water [6].

Dissolved organic matter is the major form of the organic carbon contained in the world's oceans. The majority of marine DOM is autochthonous (produced in the marine environment by phytoplankton). However in coastal seas about $70 \%$ of DOM have terrestrial origin [7], and it represents only about $2-3 \%$ of the total oceanic DOM pool [8]. The terrestrial and anthropogenic organic matter carried by river into the Baltic Sea, affected by marine microbial decomposition and photooxidation processes, is characterized by different humification degree, that reflect the changes in their molecular structure affecting the spectrum of sunlight passing through a seasurface. Fluorescence spectroscopy can provide an excellent tool to source DOM fractions, and to monitor and understand DOM transformations in aquatic systems, as much DOM has an intrinsic fluorescence $[9,10]$. The fluorescence spectroscopy can reveal the presence of terrestrial and anthropogenic and marine humic-like components of marine FDOM via the occurrence of specific excitation/emission bands [7,11]. Another 


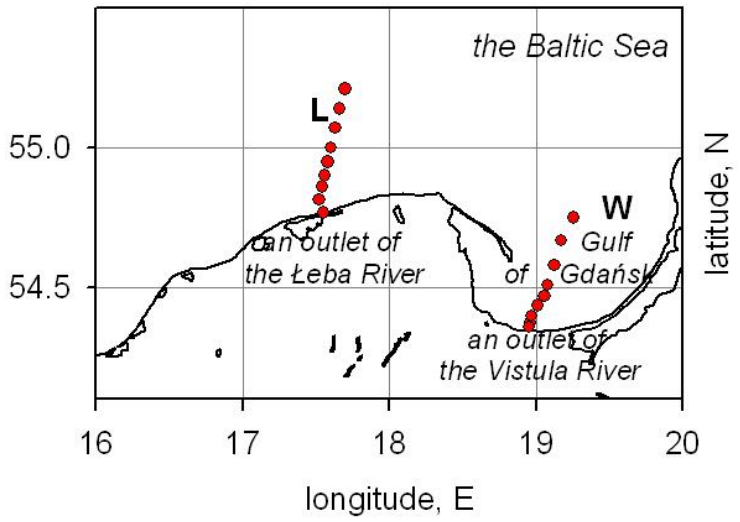

FIG. 1 Map of sampling stations along the transects $W$ and L (from the outlet of the Rivers Vistula and Łeba, respectively). In 2013: May and October ( $L$ and $W$ ) in 2014: April and October (W).

way to differentiate the sources of humic substances in seawater is based on the fact that as fluorescing molecules become more condensed in humification process, their emission spectra tend to shift toward longer wavelength [12]. The biodegradation processes change the physical, chemical and biological properties of organic molecules and effect the degree of humification, characterized by increases in aromatic (phenolic) groups and highly substituted unsaturated systems [13]. "Humification index" (HIX) calculated as a ratio between a longwavelength emission band and a short-wavelength emission band excited at UV [14, 15] or as a total intensity of emission spectra excited in blue light [13] is used to quantify the degree of DOM humification. In our analysis a procedure proposed by Zsolnay was applied [14].

The optically active organic molecules, specially chromophoric DOM, contained in surface and subsurface layers and an information about enrichments of the SML in CDOM as well as the humification degree of organic matter contained in SML and SS are the subject of our analyses. The aim of this paper is (i) to characterize the fluorescent dissolved organic matter FDOM in the SML and SS in the Baltic Sea with, (ii) to compare the FDOM composition in SML and SS, (iii) to describe the spatial and seasonal variability of FDOM properties in SML and SS in the Baltic Sea.

\section{METHODOLOGY}

Samples were collected during the last days of five research cruises: three field studies were conducted in 2013: May (7$13^{\text {th }}$ and $\left.15-31^{\text {st }}\right)$ and $\left(2-17^{\text {th }}\right)$ October; and two were conducted in 2014: April (1-9 $\left.9^{\text {th }}\right)$ and October $\left(7-21^{\text {st }}\right)$. Sampling was carried along transects from the mouths of the Vistula River and the Łeba River into the open sea. The SML samples were collected by a metal Garret's net of $500 \mu \mathrm{m}$ mesh. This technique allows collecting water from the top-layer of approximately 1 millimeter [16]. In the same places the SS samples were taken by a Niskin bottle. Sampling was carried out when the sea state was 1-4 B only, and there were no detectable oil spills. The unfiltered samples were placed into dark bottles and stored at $4^{\circ} \mathrm{C}$. During sampling the measurements of temperature and salinity of a surface layer were made.
Spectrofluorometric measurements of the samples were carried out in 24 hours after collection without any previous treatment at room temperature using a $1 \mathrm{~cm}$ high sensitivity quartz cell. It is well-known that filtration separates particulate fraction from dissolved and colloidal ones. On the other hand, during filtration the strongly surface active molecules or macromolecules might be retained on the filter by sorption processes [17]. Ćosović reported that the concentration of surface active organic molecules change about several to $15 \%$ between filtered and unfiltered samples collected in the northern Adriatic Sea [17]. Furthermore, the interference of in situ measurements of CDOM fluorescence by particles was studied by Belzile who estimated a possible error in fluorescence signal retrieval in less than $4 \%$ [18]. Taking into account the above the all studied samples are analyzed without filtration. The 96 samples, from 48 stations, were collected during the five Baltic cruises and the 3D EEM (Excitation Emission Matrix) fluorescence spectra of the samples were measured. The 3D steady-state fluorescence spectra (3D EEMs) of the samples and a milliQ water were carried out using VARIAN Cary Eclipse spectrofluorometer with $5 \mathrm{~nm}$ bandwidth in both excitation and emission, respectively. The excitation of the 3D EEM was fixed in a spectral range $250-500 \mathrm{~nm}$, with a step $10 \mathrm{~nm}$. The emission of the 3D EEM was recorded in a spectral range 300-600 nm, with a step $5 \mathrm{~nm}$. Firstly the 3D EEM of miliQ water - as a reference signal - was measured each time after the cruise and the intensity of the Raman emission band (the area below the Raman emission curve), excited at $355 \mathrm{~nm}$, was calculated. Normalization of 3D EEM of samples and conversion into Raman units (R.U.) was performed by subtracting the 3D EEM of milliQ water from 3D spectra of the samples and then dividing them by the intensity of Raman band calculated for miliQ water.

Due to the variability and complexity of the chemical composition of the marine organic matter the best tool for the identification of organic molecules in seawater is fluorescence spectroscopy [10]. Optically active parts of molecules, chromophores or fluorophores, possess their unique characteristic absorption and/or fluorescence spectra that allow their identification. That enable to identify of the sources of organic matter in the sea. Analysis of 3D EEM fluorescence spectra of marine waters was based on identification of distinct fluorescence intensity peaks based on the interpretation proposed by Coble [11]. Fluorescence intensities of the 3D EEM spectral bands representing the main DOM components belonging to the A-like, M-like, C-like and T-like fractions were proposed and calculated for Baltic seawater by Kowalczuk and Drozdowska [19]-[21]. The spectral characteristic (energies) positions of excitation and emission wavelengths of the main components of marine DOM at the 3D spectrum are listed at first two columns of the Table 1 .

Humification index was calculated as the ratio of the intensities of the long-wavelength band (434-480 nm) to the shortwavelength band (330-346 nm) of the fluorescence spectrum excited at $255 \mathrm{~nm}$. The ratio $(\mathrm{M}+\mathrm{T}) /(\mathrm{A}+\mathrm{C})$, resulting from calculations of the intensities of the main FDOM components is used to access the relative contribution of recently produced DOM to highly degraded DOM. 


\begin{tabular}{|c|c|c|c|c|c|c|c|c|c|c|c|c|c|}
\hline \multirow{3}{*}{$\begin{array}{l}\text { Name } \\
\text { of } \\
\text { peaks }\end{array}$} & \multirow{3}{*}{$\begin{array}{l}\text { Peaks: } \\
\text { excitation/ } \\
\text { emission } \\
(\mathrm{nm} / \mathrm{nm})\end{array}$} & \multicolumn{6}{|c|}{$\begin{array}{l}\text { Medians of fluorescence intensities in peaks } \\
\text { of FDOM components in spring (S) and } \\
\text { autumn (A) in SML/ Raman unit }\end{array}$} & \multicolumn{6}{|c|}{$\begin{array}{l}\text { Medians of fluorescence intensities in peaks } \\
\text { of FDOM components in spring (S) and } \\
\text { autumn (A) in SS/Raman unit }\end{array}$} \\
\hline & & \multicolumn{2}{|c|}{ Salinity $>7$} & \multicolumn{4}{|c|}{ Salinity $<7$} & \multicolumn{2}{|c|}{ Salinity $>7$} & \multicolumn{4}{|c|}{ Salinity $<7$} \\
\hline & & $\mathrm{S}$ & A & $\mathrm{S}$ & A & $\begin{array}{l}\text { linear. } \\
\text { corr. } \\
\mathrm{r}^{2}\end{array}$ & $\begin{array}{l}\text { reg. } \\
\text { coef. } \\
\text { a }\end{array}$ & $\mathrm{S}$ & A & $\mathrm{S}$ & A & $\begin{array}{c}\text { linear } \\
\text { corr. } \\
\mathrm{r}^{2}\end{array}$ & $\begin{array}{l}\text { reg. } \\
\text { coef. } \\
\text { a }\end{array}$ \\
\hline A & $250 / 437$ & 0.328 & 0.315 & 1.038 & 0.237 & 0.93 & -0.28 & 0.299 & 0.288 & 0.650 & 0.239 & 0.64 & -0.21 \\
\hline $\mathrm{C}$ & $310 / 429$ & 0.192 & 0.170 & 0.603 & 0.177 & 0.97 & -0.17 & 0.162 & 0.151 & 0.367 & 0.166 & 0.59 & -0.13 \\
\hline $\mathrm{M}$ & $300 / 387$ & 0.194 & 0.168 & 0.442 & 0.150 & 0.89 & -0.12 & 0.154 & 0.149 & 0.297 & 0.153 & 0.59 & -0.09 \\
\hline $\mathrm{T}$ & $270 / 349$ & 0.152 & 0.178 & 0.276 & 0.109 & 0.39 & -0.04 & 0.121 & 0.128 & 0.237 & 0.107 & 0.29 & -0.03 \\
\hline
\end{tabular}

TABLE 1 The analysis of $3 D$ fluorescence spectra of the samples collected from SML and SS along $W$ and $L$ transects during spring and autumn cruises.

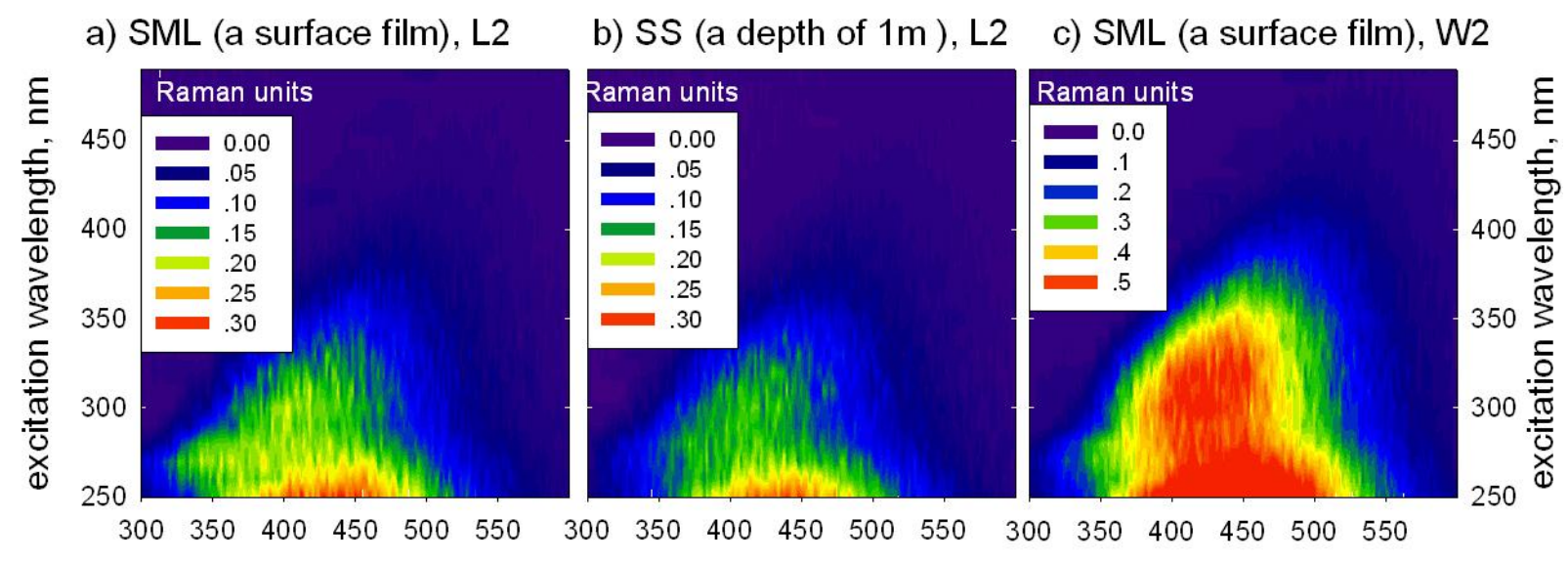

fluorescence wavelength, $\mathrm{nm}$

FIC. 2 Typical 3D EEMs for: (a) SS and (b) SML samples - at the station near the Łeba River outlet (L2) and (c) SML - at the station near the Vistula River outlet (W2).

\section{RESULTS}

\subsection{Spatial and seasonal variability of FDOM in the surface microlayer and subsurface layer in the Baltic Sea}

The higher fluorescence intensities in all emission bands were observed in samples collected in a SML than a SS layer. There was a consistent pattern that $\mathrm{A}, \mathrm{M}, \mathrm{C}$, and T peak intensities were higher in the SML than in the SS layer. The example of observed differences is shown in Figure 2(a) and 2(b), which presents the measured EEM in the SML and SS samples collected at the station L2 near the port Łeba, on transect L, at $15^{\text {th }}$ October 2013. For this particular example the fluorescence intensities in SML were as follow: A-peak - 0.292 R.U., M-peak - 0.166 R.U., C-peak - 0.165 R.U., T-peak - 0.180 R.U., respectively. The fluorescence intensities of corresponding peaks in the sample collected in the SS layer were lower: A-peak - 0.277 R.U., M-peak - 0.143 R.U., C-peak - 0.144 R.U., T-peak - 0.116 R.U., respectively. This pattern has been consistent for both sampled transects and seasons: the EEM intensity in the SML is higher than in SS layer. We have observed the spatial and seasonal differences in FDOM intensities at all selected peaks. Spatial distribution of measured EEM intensities is mostly related with input of terrestrial DOM into the Baltic Sea and amount of fresh water discharge. Figures 2(c) and 2(a) present the differences in the EEM intensity measured in the SML at two sampling site: one located at vicinity of the Vistula River mouth (W2) and second located at vicinity of the Łeba River mouth (L2), at $16^{\text {th }}$ and $15^{\text {th }}$ October, 2013, respectively.
The EEM intensities at SML near the Vistula River mouth were 2.8, 2.6, 3.1 and 1.5 times higher at respective peaks A, M, C and $\mathrm{T}$ than EEM intensities measured in the SML at the Łeba River mouth. The differences in the EEM peak intensity can be attributed to the river discharge: on average the Vistula River discharge in an order of magnitude larger than the Łeba River.

Differences in spatial and seasonal variations in measured EEM peak intensities in the SML and SS layer were quantify by calculating the median and percentile distribution in spring and autumn in two water masses: one characterized by salinity $<7$, which is influenced by direct fresh water discharge from rivers and second characterized by salinity $>7$, which is typical for open Baltic Sea waters. Table 1 contains median values of fluorescence intensities of respective peaks in the SML and SS layer in spring and autumn in distinct water masses. The percentiles statistical distribution of fluorescence peaks in the SML and SS layer in two seasons in water masses characterized by salinity threshold less that 7 and higher than 7, have been presented in Figures 3 and 4 . The box-whisker plots in Figures 3 and 4 present median values (solid line), $25^{\text {th }}$ and $75^{\text {th }}$ percentile (the boundaries of the box: closest to and farthest from zero, respectively) and $10^{\text {th }}$ and $90^{\text {th }}$ percentiles (whiskers below and above the box, respectively) of the respective fluorescence intensity. There has been a clear seasonal pattern shown on both figures that the higher median values were observed in the SML than in SS. The A-peak intensity median values observed in open Baltic Sea waters in the SML were 0.328 R.U. in spring, 0.315 R.U. 


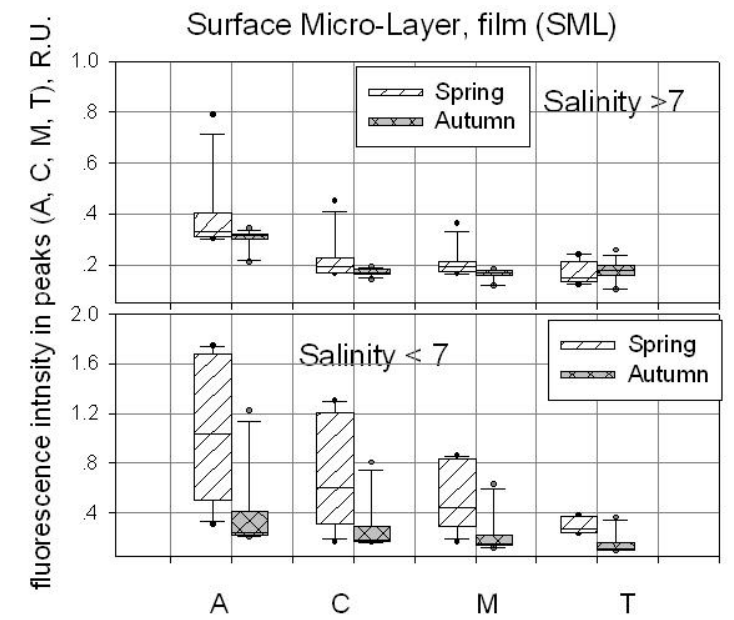

FIG. 3 The box plots of the intensities of fluorescence bands of the main components of marine FDOM in open waters (salinity > 7 ) and coastal zone (salinity < 7 ) for spring and autumn seasons - samples from a surface microlayer (SML).

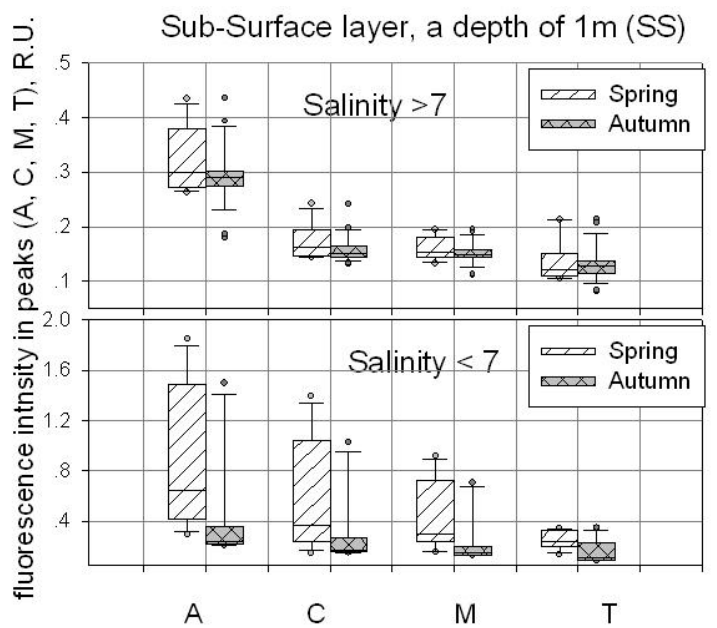

FIG. 4 The box plots of the intensities of fluorescence bands of the main components of marine FDOM in open waters (salinity > 7) and coastal zone (salinity < 7) for spring and autumn seasons - from a subsurface layer, a depth of $1 \mathrm{~m}$ (SS).

in autumn and in the SS layer was 0.299 R.U. an 0.288 R.U., in respective seasons. Similar pattern has been also observed in open Baltic waters for median values of fluorescence intensity for other respective peaks in spring and autumn (Cpeak: SLM - 0.192 R.U. and 0.170 R.U., SS - 0.162 R.U. and 0.151 R.U.; M-peak median SML - 0.194 R.U. and 0.168 R.U., SS - 0.154 R.U., 0.149 R.U.; T-peak median SML - 0.15 R.U. and 0.17 R.U., SS - 0.12 R.U. and 0.12 R.U.). The same pattern was observed in the less saline waters $<7$, although observed median values of all peaks and both in SML and SS layer were 2-3 times higher compared to open Baltic Sea waters. The median values of most of respective peaks intensities are higher in spring than in autumn both in the SML and SS layer. There was one exception, the autumn median value of the T-peak fluorescence intensity in the SML in open Baltic Sea waters was higher than spring T-peak median value. This difference was not observed in the subsurface layer, suggesting that protein like FDOM component could be accumulated in SML as the effect of photo-bleaching. Additionally, the boundaries of the boxes show much greater dispersion of the results in spring than in autumn and greater variation in coastal zone (salinity $<7$ ) than in open sea (salinity $>7$ ).

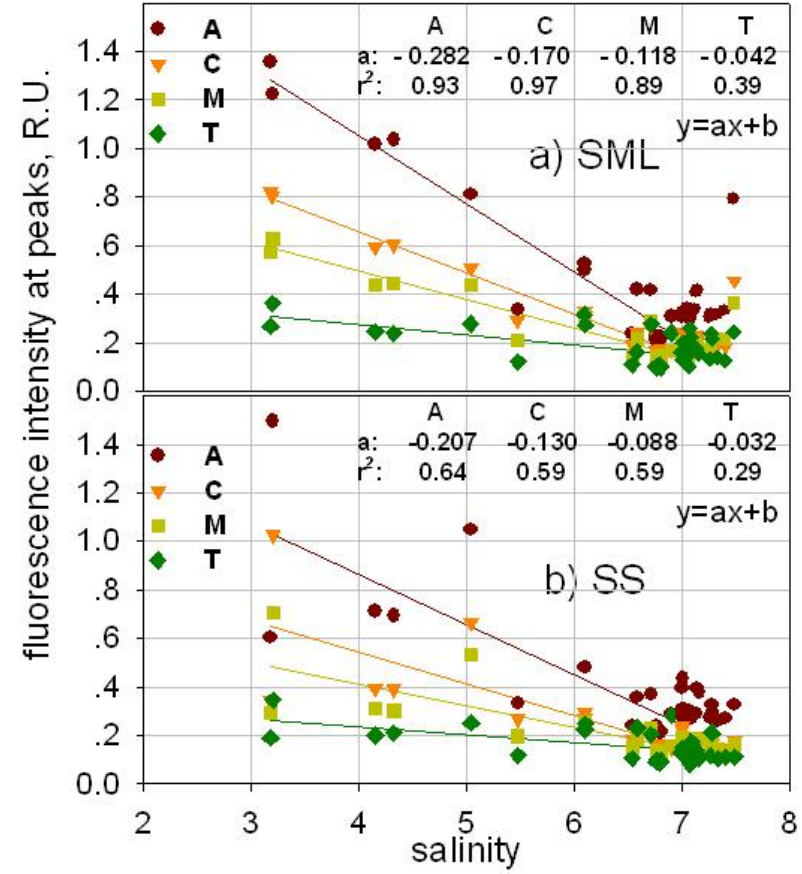

FIC. 5 The changes of fluorescence intensities at peaks (A, C, M and T) in relation to the water salinity, and linear regressions for salinity $<7$, for (a) the SML and (b) SS samples.

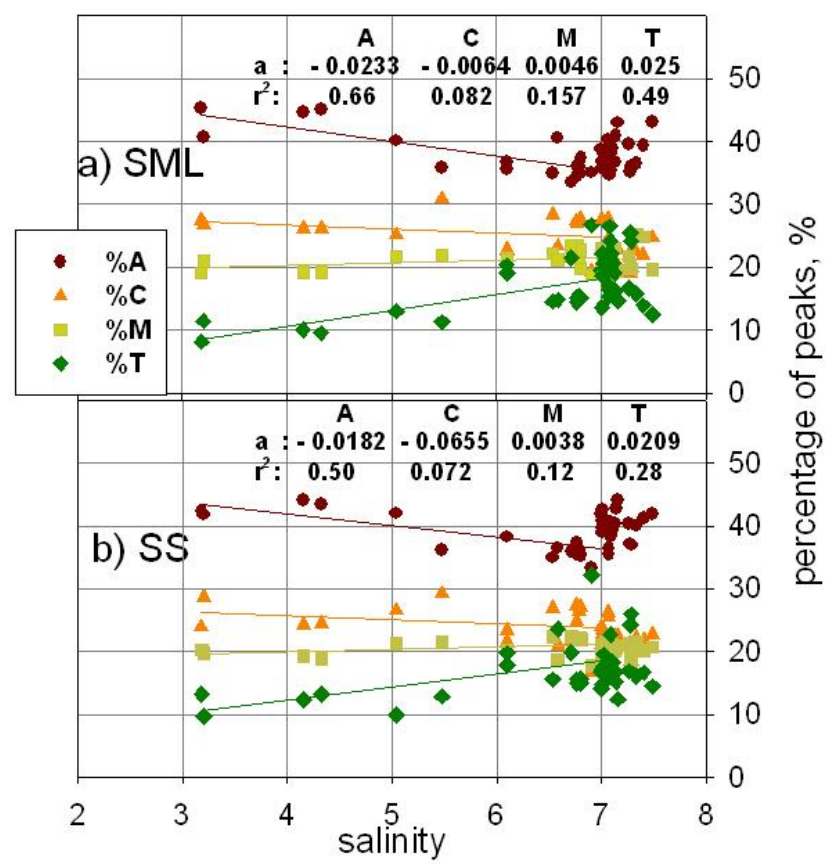

FIG. 6 The changes of the percentage of the main peaks in relation to the water salinity, and linear regressions for salinity $<7$, for (a) the SML and (b) SS samples.

The relationships between the fluorescence intensities of the main fluorescence bands as well as the relative contribution of components in a sample and salinity have been demonstrated in Figures 5 and 6. Distribution of fluorescence intensities of respective peak as the function of salinity presented in the upper graphs refers to the SML, while that shown on the lower graph refers to SS samples. The fluorescence intensities of all components decrease linearly with increasing the salinity from 3.1 to 7 and they reach almost constant values for salinity $>7$ for both SML and SS samples. Linear regressions, marked by straight lines, and their respectively regression and correlation coefficients, $a$ and $r^{2}$ for given fluorescence peaks have been presented on graphs. The highest 


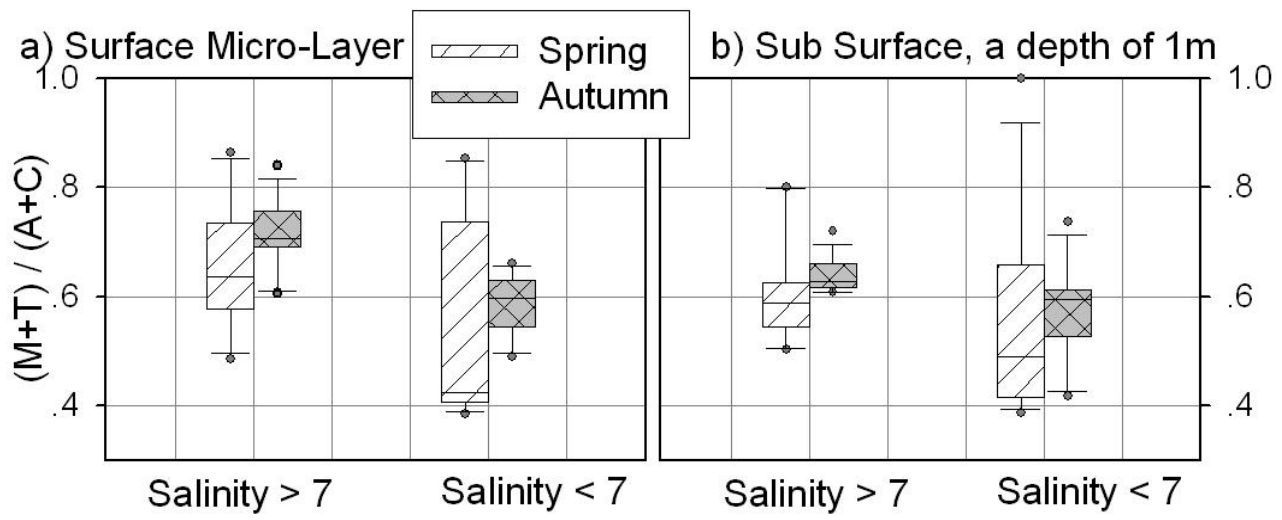

FIG. 7 The values of the $(M+T) /(A+C)$ ratio for open and coastal waters, salinity $>7$ and $<7$ respectively, in spring and autumn seasons for (a) a surface microlayer (SML) and (b) subsurface layer, at a depth of $1 \mathrm{~m}$ (SS).

\begin{tabular}{|c|c|c|c|c|c|c|c|c|c|c|c|c|}
\hline & \multicolumn{6}{|c|}{$\begin{array}{l}\text { Medians of the }(\mathrm{M}+\mathrm{T}) /(\mathrm{A}+\mathrm{C}) \text { ratio in spring }(\mathrm{S}) \\
\text { and autumn }(\mathrm{A})\end{array}$} & \multicolumn{6}{|c|}{ Medians of HIX in spring (S) and autumn (A) } \\
\hline & \multicolumn{2}{|c|}{ Salinity $>7$} & \multicolumn{4}{|c|}{$\begin{array}{l}\text { Salinity }<7 \\
\end{array}$} & \multicolumn{2}{|c|}{ Salinity $>7$} & \multicolumn{4}{|c|}{ Salinity $<7$} \\
\hline & $\mathrm{S}$ & $\mathrm{A}$ & S & A & linear. corr. $r^{2}$ & reg. coef. $a$ & $\mathrm{~S}$ & $\mathrm{~A}$ & S & $\mathrm{A}$ & linear corr. $r^{2}$ & reg. coef. $a$ \\
\hline SML & 0.64 & 0.72 & 0.41 & 0.6 & 0.55 & 0.074 & 7.1 & 4.9 & 16.3 & 5.3 & 0.78 & -3.49 \\
\hline SS & 0.59 & 0.62 & 0.49 & 0.59 & 0.38 & 0.062 & 7.2 & 6.7 & 13.3 & 4.95 & 0.72 & -2.6 \\
\hline
\end{tabular}

TABLE 2 Medians of the $(M+T) /(A+C)$ ratio and HIX of the samples collected from SML and SS during spring and autumn cruises.

value of a regression coefficient, that describes the fastest decline of fluorescence signal in SML, was obtained for peak $\mathrm{A}$, $a_{A}=-0.2824$. Other peaks declined slower, and the regression coefficients values were as follow: $-0.1699,-0.1176$ and -0.0423, for peaks C, M and T, respectively. Similar trend in distribution of fluorescence intensities of main DOM fraction occurred in the SS. Calculated regression coefficients values were as follow: $-0.2067,-0.1297,-0.0884$ and -0.032 , for A, C, M and $\mathrm{T}$ peaks respectively, Figure 5 . The rate of decrease of fluorescence intensities of all main peaks was higher in the SML compared to SS - i.e. values of corresponding regression coefficients are higher in the surface microlayer than in the subsurface layer. The relative contribution of the main components, calculated as a ratio of a fluorescence intensity of one component to a sum of all components (e.g. a percentage of A component is $\mathrm{A} /(\mathrm{A}+\mathrm{C}+\mathrm{M}+\mathrm{T}))$ varies with an increase of salinity as well, see Figure 6. Contributions of $A$ and $C$ components decrease while $\mathrm{M}$ and $\mathrm{T}$ increase, additionally the changes go faster in SML than SS and are described by the regression coefficients: -0.0233 and $-0.0182,-0.0064$ and $-0.0655,0.0046$ and $0.0038,0.025$ and 0.0209 for A, C, M, T, for SML and SS respectively. Additionally, they reach almost constant values for salinity $>7$. The near the same linear changes of fluorescence intensities and their relative contribution confirm that a surface microlayer contains the same organic molecules as subsurface water [20].

\subsubsection{Sources of FDOM in the surface microlayer and subsurface layer in the Baltic Sea}

The examination of the sources of fluorescing organic fractions are based on calculations of the $\beta: \alpha$ ratio, proposed by Parlanti [22] and Wilson [27], where the $\beta: \alpha$ ratio was calculated, from a fluorescence spectrum (obtained for excitation at $310 \mathrm{~nm})$, as a ratio of the emission intensity at 380-410 $\mathrm{nm}(\beta$ region) divided by the emission intensity observed between $420-435 \mathrm{~nm}$ ( $\alpha$ region) [22, 27]; and values $>1$ indicate that DOM is primarily of autochthonous origin and values $<0.6$ indicate primarily allochthonous origin [28]. We use the signals from M-like and T-like fluorophores, associated with the rapid degradation or transformation of microbially derived, protein-like DOM as a short-wavelength band $\beta$, as well as from A-like and C-like ones, controlled by loading of more highly degraded humic-like compounds for $\alpha$. We investigate the sources of FDOM molecules in the study area by analysis of the $(\mathrm{M}+\mathrm{T}) /(\mathrm{A}+\mathrm{C})$ ratio and by calculating its median and percentile distribution in spring and autumn in two water masses: one characterized by salinity $<7$, which is influenced by direct fresh water discharge from rivers and second characterized by salinity $>7$, which is typical for open Baltic Sea waters. Table 2 contains median values of the $(\mathrm{M}+\mathrm{T}) /(\mathrm{A}+\mathrm{C})$ ratio of the SML and SS samples in spring and autumn. The percentiles statistical distribution of the $(\mathrm{M}+\mathrm{T}) /(\mathrm{A}+\mathrm{C})$ ratio in the SML and SS layer in two seasons in water masses characterized by salinity threshold less that 7 and higher than 7 , have been presented on graphs in Figure 7. The box-whisker plots in Figures 7(a) and 7(b) present median values (solid line), $25^{\text {th }}$ and $75^{\text {th }}$ percentile (the boundaries of the box: closest to and farthest from zero, respectively) and $10^{\text {th }}$ and $90^{\text {th }}$ percentiles (whiskers below and above the box, respectively) of the respective values of the ratio. There has been a clear seasonal pattern shown in both figures that the median yields lower values in springs and higher in autumns (0.64 and 0.72) and (0.59 and 0.62) for SML and SS samples respectively, as well as reveals higher values for the SML than SS samples, in open waters (salinity $>7$ ). However in coastal zone (salinity $<7$ ) the $(\mathrm{M}+\mathrm{T}) /(\mathrm{A}+\mathrm{C})$ ratio varies with salinity and reveals greater dispersion of the results. The analysis of the $(\mathrm{M}+\mathrm{T}) /(\mathrm{A}+\mathrm{C})$ ratio indicates that in open sea (salinity $>7$ ) about 70\% (in SML) and $50 \%$ (in SS) of FDOM molecules have a mixed autochtho- 


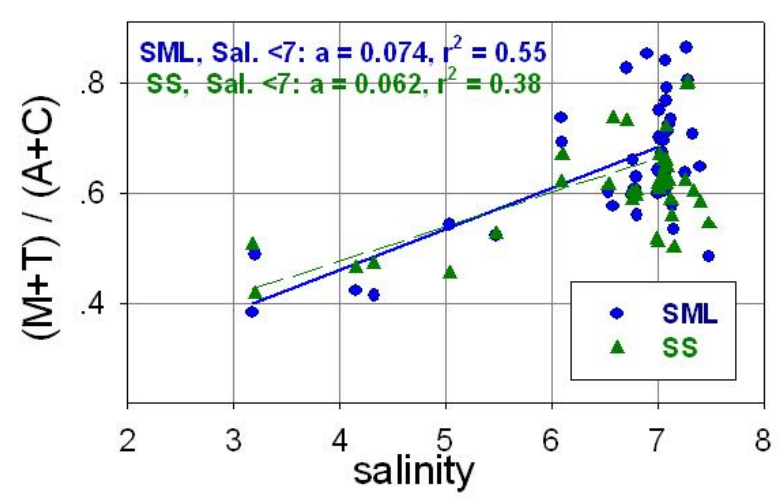

FIG. 8 The values of the $(M+T) /(A+C)$ ratio for open and coastal waters, salinity $>7$ and $<7$ respectively and linear regressions for the data from both layers for salinity $>7$.

nous and allochthonous origin during spring season - i.e. value of the ratio $>0.6$ and $<1$, while $100 \%$ of FDOM (in both layers) during autumn. The rest of FDOM molecules have an allochthonous origin - i.e. values of the ratio $<0.6$. However in estuary waters (salinity $<7$ ) a majority (about $75 \%$ ) have an allochthonous origin - i.e values of the ratio $<0.6$, in both layers and seasons as well. The rest of FDOM molecules have a mixed origin - i.e. values of the ratio $>0.6$ and $<1$. This is, because the $(\mathrm{A}+\mathrm{C})$ region (long-wavelength band in $3 \mathrm{D}$ fluorescence spectra), controlled by loading of more highly degraded humic-like compounds carrying with riverine waters, causes low values of the ratio, while the presence of in-situ produced molecules, manifested by the $(\mathrm{M}+\mathrm{T})$ region (shortwavelength band in 3D fluorescence spectra) associated with the rapid degradation or transformation of microbially derived, protein-like DOM, causes higher values of the ratio in SML than SS and in open sea samples.

The relationship between the $(\mathrm{M}+\mathrm{T}) /(\mathrm{A}+\mathrm{C})$ ratio and salinity is demonstrated in Figure 8. The values of the ratio increase linearly with increasing the salinity from 3.1 to 7 . Linear regressions, marked by straight line curves, and their regression and correlation coefficients, $a$ and $r^{2}$ respectively are presented on a graph. The regression coefficients regarding to both: the SML and SS describe similar values: 0.074 and 0.062 , respectively. The values of the ratio recorded for salinity $>7$ are presented by their medians and put in Figure 7 for SML and SS samples, respectively.

\subsubsection{Humification of FDOM in the surface microlayer and subsurface layer in the Baltic Sea}

Next, the HIX index is simple and easy to calculate and sensitive to changes in the molecular weight of DOM molecules and to assess the aromaticity of DOM (ratio of $\mathrm{C} / \mathrm{H}$ ) was calculated. This parameter tells about an increase in the $\mathrm{C} / \mathrm{H}$ in DOM molecules that at the same time cause the red-shift of the fluorescence [23, 24]. Figure 9 presents the box plots of HIX parameter calculated for the SML and SS samples. The percentiles statistical distribution of HIX parameter in the SML and SS layer in two seasons, in two water masses characterized by salinity threshold less that 7 and higher than 7 , have been presented in graphs in Figure 9. The box plots in Figures 9(a) and 9 (b) present median values (solid line), $25^{\text {th }}$ and $75^{\text {th }}$ percentiles (the boundaries of the box: closest to and farthest from zero, respectively) and $10^{\text {th }}$ and $90^{\text {th }}$ percentiles (whiskers be- low and above the box, respectively) of the respective values of HIX. There has been a clear seasonal pattern shown in both figures that the median yields higher values in springs and lower in autumns (7.1 and 7.2) and (4.9 and 6.7) for SML and SS samples respectively, as well as HIX index yields higher values in SS (7.2 and 6.7) than in SML (7.1 and 4.9) samples, for both spring and autumn respectively. In coastal waters (salinity $<7$ ) the HIX varies with salinity and reveals greater dispersion of the results.

The relationships between HIX parameter and salinity are demonstrated in Figure 10. The values of HIX decrease linearly with increasing salinity from 3.1 to 7 and linear regression coefficients yield similar values, however a little higher for SML $(-3.486)$ than for SS (-2.601) samples. Analysis of the boundaries of the boxes show greater variation of HIX in SML. Additionally, the higher values of the HIX obtained for coastal water, salinity $<7$, reveal strong humification caused additionally by solar radiation [25].

\section{DISCUSSION}

The analysis of EEM spectra measured for SML and SS samples revealed a seasonal pattern for amount of fluorescing fractions of organic matter in surface seawater masses characterized by salinity $<7$ and $>7$. It could be concluded that, concentration of the all organic matter fractions in coastal waters decreases with increasing a distance from land and salinity due to dilution of fresh water during mixing with marine waters as well as because terrestrial, big molecules sink to the bottom and small one are flocculated [26].

Investigations of the sources of fluorescing organic fractions are based on analysis of the $(\mathrm{M}+\mathrm{T}) /(\mathrm{A}+\mathrm{C})$ ratio. Low values $(<0.6)$ of the $(\mathrm{M}+\mathrm{T}) /(\mathrm{A}+\mathrm{C})$ ratio received in studied waters of the Southern Baltic indicate that the freshwater inflow is a main source affecting the marine FDOM composition, especially in spring and in estuary waters (salinity $<7$ ), while in SML the values increase a little - manifesting the presence of in-situ produced molecules. The HIX index is a good factor to measure the humification degree, given that as fluorescent molecules become more condensed, their emission spectra tend to shift toward longer wavelengths [29]. So, the HIX value reflects the structural changes that occur during the humification process and is directly proportional to humic content of DOM [14], [30]-[34]. HIX reaches higher values in SS water samples than in SML in open sea waters, while in coastal waters the both layers are almost equally affected by humification process. As was to be expected the $(\mathrm{M}+\mathrm{T}) /(\mathrm{A}+\mathrm{C})$ ratio is inversely related to humic content of DOM (HIX).

\section{CONCLUSIONS}

Studies of 3D fluorescence spectra of samples collected, from SML and SS layer, along transects from the river outlets to open sea allowed to calculate the fluorescence maxima of the main peaks of marine FDOM and to analyze their sources. The fluorescence intensities of the main peaks of marine FDOM (A-peak, M-peak, C-peak T-peak) reveal: (i) concen- 
a) Surface Micro-Layer (SML) b) Sub - Surface, a depth of $1 \mathrm{~m}$

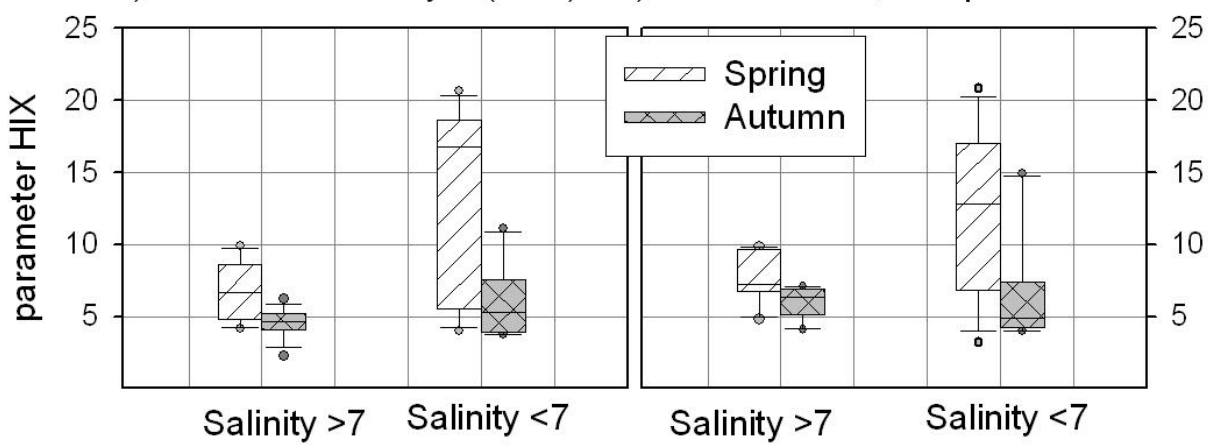

FIG. 9 The values of HIX parameter for (a) a surface microlayer (SML) and (b) subsurface layer, at a depth of $1 \mathrm{~m}$ (SS), for open and coastal waters, salinity > 7 and $<7$ respectively, in spring and autumn seasons.

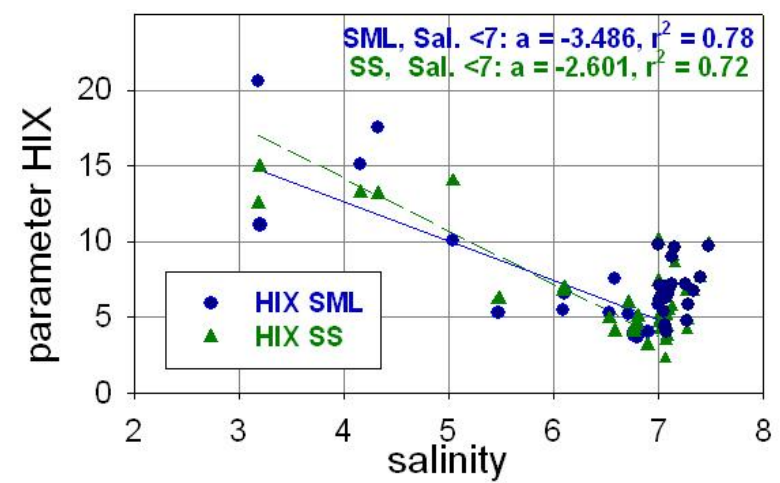

FIG. 10 The values of HIX parameter for a surface microlayer (SML) and subsurface layer, at a depth of $1 \mathrm{~m}$ (SS), for open and coastal waters, salinity $>>$ and $\langle>$ respectively, and a linear regression for the data from both layers obtained for salinity < 7 .

tration of fluorescing molecules is higher in SML than is SS, (ii) concentration of FDOM is 2-3 times higher in coastal region (salinity $<7$ ) than in open sea $(>7$ ), (iii) the greater variation of fluorescence intensities was recorded in spring than in autumn, (iv) low values of the $(\mathrm{M}+\mathrm{T}) /(\mathrm{A}+\mathrm{C})$ ratio indicate that the freshwater inflow is a main source affecting the marine FDOM composition in springs, while the values increase a little in SML in open sea waters, manifesting the presence of in-situ produced molecules there, (v) in open waters HIX reaches higher values in SS samples than in SML that means the SS is enriched in molecules with high molecular weight and higher aromaticy, (vi). while in coastal waters (salinity $<7$ ) - with high concentration of organic molecules affected by a strong humification process and under the influence of bacterial activity - both layers are almost equally affected.

Content and composition of FDOM - both in the SML and SS - depend on seasons and greater variability were observed in spring and in SML. The organic molecules contained in the SML can modify many physical processes connected with surface films, thus a study on certain physical properties of a surface microlayer is needed in the future.

\section{ACKN OWLEDGEMENTS}

This paper was partially supported by the project "Satellite Monitoring of the Baltic Sea Environment - SatBałtyk funded by European Union through European Regional Development Fund contract No. POIG 01.01.02-22-011/09. The authors are grateful to colleques from the Air-Sea Interaction Laboratory of the Institute of Oceanology Polish Academy of Sciences, M.Sc. Dorota Gutowska, M.Sc. Paulina Pakszys, M.Sc. Przemysław Makuch and M.Sc. Piotr Markuszewski for assist in collecting the sea samples.

\section{References}

[1] A. Soloviev, and R. Lukas, Near-surface layer of the ocean: structure, dynamics and applications (Springer, Berlin, 2006).

[2] P. S. Liss, and R. A. Duce, The sea surface and global change (Cambridge University Press, Cambridge, 2005).

[3] M. A. Cunliffe, S. Engel, S. Frka, B. Gašparović, C. Guitart, J. C. Murrell, M. Salter, et al., "Sea surface microlayers: a unified physicochemical and biological perspective of the air-ocean interface," Prog. Oceanogr. 109, 104-116 (2013).

[4] Q. Gao, C. Leck, C. Rauschenberg, and P. A. Matrai, "On the chemical dynamics of extracellular polysaccharides in the high Arctic surface microlayer," Ocean Sci. 8, 401-418 ( 2012).

[5] J. M. Sieburth, and J. T. Conover, "Slicks associated with Trichodesmium blooms in the Sargasso sea," Nature 205, 830-831 (1965).

[6] M. Cunliffe, R. C. Upstill-Goddard, and J. C. Murrell, "Microbiology of aquatic surface microlayers," FEMS Microbiol. Rev. 35, 233-246 (2011).

[7] P. Coble, "Marine optical biogeochemistry: the chemistry of ocean color," Chem. Revi. 107, 402-418 (2007).

[8] S. Opsahl, and R. Benner, "Distribution and cycling of terrigenous dissolved organic matter in the ocean," Nature 386, 480-482 (1997).

[9] J. R. Lakowicz, Principles of fluorescence spectroscopy (third edition, Plenum Press, New York, 2006).

[10] N. Hudson, A. Baker, and D. Reynolds, "Fluorescence analysis of dissolved organic matter in natural, waste and polluted waters-a review," River Res. Appl. 23, 631-649 (2007).

[11] P. Coble, "Characterization of marine and terrestrial DOM in seawater using excitation-emission matrix spectroscopy," Mar. Chem. 51, 325-346 (1996).

[12] H. Haken, and H. C. Wolf, Molecular physics and elements of quantum chemistry: introduction to experiments and theory (Springer Verlag, Berlin, 1995).

[13] D. Milori , L. Martin-Neto, C. Bayer, J. Mielniczuk, and V. Vagnato, "Humification degree of soil humic acids determined by fluorescence spectroscopy," Soil Sci. 167, 739-749 (2002). 
[14] A. Zsolnay, E. Baigar, M. Jimnez, B. Steinweg, and F. Saccomandi, "Differentiating with fluorescence spectroscopy the sources of dissolved organic matter in soils subjected to drying," Chemosphere 38, 45-50 (1999).

[15] K. Kalbitz, W. Geyer, and S. Geyer, "Spectroscopic properties of dissolved humic substances-a reflection of land use history in a fen area," Biogeochemistry 47, 219-238 (1999).

[16] W. D. Garrett, "Collection of slick-forming materials from the sea surface," Limnol Oceanogr. 10, 602-605 (1965).

[17] B. Ćosović, and V. Vojvodić, "Voltammetric analysis of surface active substances in natural seawater," Electroanal. 10, 429-434 (1998).

[18] C. Belzile, C. S. Roesler J. P. Christensen, N. Shakhova, and I. Semiletov, "Fluorescence measured using the WETStar DOM fluorometer as a proxy for dissolved matter absorption," Estuar. Coast. Shelf S. 67, 441-449 (2006).

[19] P. Kowalczuk, J. Ston-Egiert, W. J. Cooper, R. F. Whitehead, and M. J. Durako, "Characterization of chromophoric dissolved organic matter (CDOM) in the Baltic Sea by excitation emission matrix fluorescence spectroscopy," Mar. Chem. 96, 273-292 (2005).

[20] V. Drozdowska, and M. Józefowicz, "Spectroscopic studies of marine surfactants in the southern Baltic Sea," Oceanol. 57, 159-167 (2015).

[21] V. Drozdowska, W. Freda, E. Baszanowska, K. Rudź, M. Darecki, J. R. Heldt, and H. Toczek, "Spectral properties of natural and oil polluted Baltic seawater - results of measurements and modeling," Eur. Phys. J-Spec. Top. 222, 1-14 (2013).

[22] E. Parlanti, K. Wörz, L. Geoffroy, and M. Lamotte, "Dissolved organic matter fluorescence spectroscopy as a tool to estimate biological activity in a coastal zone submitted to anthropogenic inputs," Org. Geochem. 31, 1765-1781 (2000).

[23] Y.-P. Chin, G. Aiken, and E. O'Loughlin, “Molecular weight, polydispersity, and spectroscopic properties of aquatic humic substances," Environ. Sci. Technol. 28, 1853-1858 (1994).
[24] D. M. McKnight, R. Harnisch, R. L. Wershaw, J. S. Baron, and S. Schiff, "Chemical characteristics of particulate, colloidal, and dissolved organic matter in Loch Vale Watershed, Rocky Mountain National Park," Biogeochemistry 36, 99-214 (1997).

[25] S. Glatzel, K. Kalbitz, M. Dalva, and T. Moore, "Dissolved organic matter properties and their relationship to carbon dioxide efflux from restored peat bogs," Geoderma 113, 397-411 (2003).

[26] S. Uścinowicz (ed.), Geochemistry of Baltic Sea, surface sediments (PIG-PIB, Warsaw, 2011).

[27] H. F. Wilson, and M. A. Xenopoulos, "Effects of agricultural land use on the composition of fluvial dissolved organic matter," $\mathrm{Na}$ ture Geosci. 2, 37-41 (2009).

[28] C. Huguet, J. Kim, G. de Lange, J. S. Sinninghe Damsté, and S. Schouten, "Effects of long term oxic degradation on the TEX86 and BIT organic proxies," Org. Ceochem. 40, 1188-1194 (2009).

[29] N. Senesi, T. M. Miano, M. R. Provenzano, and G. Brunetti, “Characterization, differentiation, and classification of humic substances by fluorescence spectroscopy," Soil Sci. 152, 259-271 (1991).

[30] T. Ohno, "Fluorescence inner-filtering correction for determining the humification index of dissolved organic matter," Environ. Sci. Technol. 36, 742-746 (2002).

[31] F. J. Stevenson, Humus Chemistry (Wiley, New York, 1982).

[32] T. M. Miano, and N. Senesi, "Synchronous excitation fluorescence spectroscopy applied to soil humic substances chemistry," Sci. Total Environ. 117, 41-51 (1992).

[33] S.-C. Tam, and G. Sposito, "Fluorescence spectroscopy of aqueous pine litter extracts: effects of humification and aluminium complexation," J. Soil Sci. 44, 513-524 (1993).

[34] C. J. Williams, Y. Yamashita, H. F. Wilson, R. Jaffe, and M. A. Xenopoulos, "Unraveling the role of land use and microbial activity in shaping dissolved organic matter characteristics in stream ecosystems," Limnol. Oceanogr. 55, 1159-1171 (2010). 